Pesq. Vet. Bras. 30(4):373-377, abril 2010

\title{
Análise histológica das glândulas uretrais da capivara (Hydrochoerus hydrochaeris) $^{1}$
}

\author{
Daniela S. Fernandez ${ }^{2}$, Rosa H.S. Ferraz ${ }^{3}$, Alan P.F. Melo ${ }^{4}$, Rosangela F. \\ Rodrigues $^{4}$ e Wilson M. Souza ${ }^{5}$
}

\begin{abstract}
Fernandez D.S., Ferraz R.H.S., Melo A.P.F., Rodrigues R.F. \& Souza W.M. 2010. [Histological analysis of urethral glands of the capybara (Hydrochoerus hydrochaeris).] Análise histológica das glândulas uretrais da capivara (Hydrochoerus hydrochaeris). Pesquisa Veterinária Brasileira 30(4):373-377. Curso de Medicina Veterinária, Universidade de Rio Preto (Unirp), Centro Universitário de Rio Preto, Rua Gabriel Yvette Atique 45, São José do Rio Preto, SP 15025-400, Brasil. E-mail: alanmelo@unirpnet.com.br

To perform a microscopic study of the glands attached to the male urethra, we used two adult capybaras (Hydrochoerus hydrocaeris) from which fragments of the urethral glands were collected, immersed in Bouin's fixative solution, washed thoroughly with $70 \%$ to absolute alcohol, submitted to routine histological techniques and stained with hematoxylin/eosin and Masson's trichromic method. The morphological findings were: Vas deferens has a thickening of the wall without granular epithelium and with unchanged lumen; the vesicular gland has a secretory epithelium of pseudostratified columnar type; the prostate gland has a high and ramified mucous membrane covered with pseudostratified cylindrical epithelium. Male capybaras have vesicular, prostate as urethral glands. In the material examined, no secretory epithelium corresponding to bulbourethral glands was identified; morphologically it resembles to the other histricomorphs.
\end{abstract}

INDEX TERMS: Urethral glands, rodents, capybara, Hydrochoerus hydrochaeris, microscopy

RESUMO.- Para realização do estudo microscópico das glândulas anexas à uretra masculina, foram utilizadas duas capivaras (Hydrochoerus hydrocaeris), adultas, das quais foram coletados fragmentos das glândulas genitais acessórias, imersos em solução fixadora de Bouin e lavados cuida-

\footnotetext{
${ }^{1}$ Recebido em 20 de julho de 2009.

Aceito para publicação em 19 de dezembro de 2009.

2 Curso de Medicina Veterinária, Universidade do Oeste (Unoeste), Rodovia Raposo Tavares Km 572, Bairro Limoeiro, Presidente Prudente, SP 19067-175, Brasil. E-mail: daniseko@unoeste.br

${ }^{3}$ Departamento de Ciências Básicas e Produção Animal (DCBPA), Faculdade de Agronomia e Medicina Veterinária, Universidade Federal de Mato Grosso (UFMT), Av. Fernando Correa da Costa 2367, Bairro Boa Esperança, Cuiabá, MT 78060900,Brasil. E-mail: rhsferraz@ufmt.br

${ }^{4}$ Curso de Medicina Veterinária, Universidade de Rio Preto (Unirp), Centro Universitário de Rio Preto, Rua Gabriel Yvette Atique 45, São José do Rio Preto, SP 15025-400, Brasil. *Autor para correspondência: alanmelo@unirpnet.com.br

${ }^{5}$ Departamento de Apoio, Produção e Saúde Animal (DAPSA), Curso de Medicina Veterinária, Universidade Estadual Paulista (Unesp), Rua Clóvis Pestana 793, Cx. Postal 341, Araçatuba, SP 16050-680, Brasil. E-mail: souzawm@fmva.unesp.br
}

dosamente em álcool de 70\% ao absoluto. A seguir foram submetidos aos processos histológicos de rotina e corados pelos métodos de Hematoxilina/Eosina e Tricrômico de Masson. Os resultados morfológicos encontrados foram: 0 ducto deferente possui um espessamento da parede, onde a luz permanece inalterada e sem presença de epitélio granular. A glândula vesicular possui um epitélio secretor do tipo pseudoestratificado colunar. A glândula prostática possui mucosa com pregueamentos altos e ramificados, revestido por epitélio pseudoestratificado cilíndrico. Machos de capivaras possuem glândulas vesiculares e próstata como glândulas uretrais. No material examinado não foi identificado epitélio secretor correspondente a glândula bulbouretral e morfologicamente assemelha-se aos outros histricomorfos.

TERMOS DE INDEXAÇÃO: Glândulas uretrais, roedores, capivaras, Hydrochoerus hydrochaeris, microscopia.

\section{INTRODUÇÃO}

Nas últimas décadas, o aumento acentuado da população humana impôs a conquista de novas fronteiras agrí- 
colas, além de uma intensa exploração do espaço já utilizado. Estes fatos nem sempre foram acompanhados de um manejo adequado do ambiente, com a determinação de consideráveis ameaças a várias espécies selvagens. A criação extensiva de alguns animais domésticos, com destaque para os bovinos e bubalinos, requereu a ocupação de grandes áreas, especialmente nos estados das regiões Centro-oeste e Norte do Brasil, onde os proprietários, além da adoção de pastagens artificiais, confeccionaram represas para o aproveitamento das nascentes naturais, e com isso geraram condições ideais para a multiplicação incontrolada da capivara, cujos hábitos alimentares podem competir com esses animais de produção. De outra parte, a criação comercial de algumas espécies selvagens, dentre as quais a capivara, é regulamentada pelo Instituto Brasileiro do Meio Ambiente e dos Recursos Naturais Renováveis (IBAMA), por meio da Instrução Normativa n 169 de 20/02/2008 (Brasil 2008), viabilizando uma atividade geradora de recursos econômicos.

Dessa forma, a capivara surge como uma alternativa aos criadores na ocupação racional de charcos e banhados, áreas frequentemente não aproveitadas ou de difícil exploração nas atividades pastoris convencionais, como pode ser verificado em diversas propriedades rurais no estado de São Paulo, especialmente nas regiões onde são disponíveis resíduos agroindustriais e restos culturais de alto potencial de aproveitamento na dieta destes vertebrados.

O valor zootécnico da capivara está relacionado primariamente à qualidade de sua carne e ao aproveitamento da pele na indústria do couro, embora haja relatos da utilização da gordura na medicina popular (Ojasti 1973). Além disso, a oferta de carne de caça, a partir de criações regulamentadas, configura a condição sustentável da atividade, diminuindo o impacto sobre as populações naturais.

Alho (1986) descreve que a espécie atinge a maturidade sexual entre 15-18 meses, quando atingem cerca de $30 \mathrm{~kg}$ de massa corpórea, embora os órgãos genitais externos, em ambos os sexos, estejam escondidos por uma prega cutânea.

O grupo dos roedores é o mais utilizado como modelo experimental. Além das espécies convencionais, muitas espécies silvestres têm sido empregadas em pesquisas, sejam para a produção de conhecimento intrínseco das espécies, ou na utilização como instrumentos de compreensão de mecanismos normais ou patológicos, especialmente aqueles vinculados a processos reprodutivos (Rodrigues et al. 2006, Conceição et al. 2008, Miglino et al. 2008). Neste contexto, embora a capivara constitua-se excelente modelo experimental na investigação do desenvolvimento de placentas hemocoriais (Miglino et al. 2004, Kanashiro et al. 2009), informações sobre a morfologia dos órgãos genitais do macho dessa espécie são escassos, em especial a descrição das glândulas genitais acessórias. Por outro lado, as glândulas genitais acessórias de outros roedores da infra-ordem Hystricognathi como a paca (Matamoros 1981, Borges 2004) e a cutia (Menezes et al. 2003, Mollinaeu et al. 2006, 2009) foram caracterizadas macro e microscopicamente.

Desta forma objetivou-se descrever nesta espécie a estrutura microscópica das glândulas uretrais (ampolares, vesiculares e próstata), com vistas a estabelecer o padrão da espécie.

\section{MATERIAL E MÉTODOS}

Para a realização deste trabalho foram utilizadas duas capivaras (Hydrochoerus hydrochaeris Linnaeus, 1766), machos e adultos, oriundas de criatório autorizado pelo IBAMA, situado na Fazenda Caramuru, município de Salmourão, Estado de São Paulo.

As glândulas uretrais, evidenciadas por dissecção a fresco, foram as glândulas vesiculares e a próstata. Após a identificação, fragmentos foram coletados de cada uma delas e imersos em solução fixadora de Bouin, por um período de 24 h. Após a fixação, os fragmentos foram desidratados em concentrações crescentes de álcool etílico, diafanizados em xilol e incluídos em parafina. Cortes de 7 micrômetros de espessura foram obtidos e corados pela Hematoxilina-Eosina e pelo Tricrômico de Masson. A leitura das lâminas histológicas, bem como a documentação digital das mesmas, foi realizada utilizando-se microscópio de campo claro Olympus BX-60.

Os procedimentos histológicos foram efetuados conforme as recomendações de Behmer et al. (1976), e, para as designações das estruturas histológicas das glândulas genitais acessórias da capivara, foi utilizada a terminologia preconizada na Nomina Histologica (ICVHN 1994).

\section{RESULTADOS}

A capivara apresenta como glândulas uretrais as glândulas vesiculares e a próstata, as quais compartilham da estrutura histológica pela presença de uma túnica mucosa, uma muscular e uma adventícia, variando entre elas a proporção e a composição dos elementos histológicos.

Glândula vesicular. A parte secretora apresenta complexo padrão de pregueamentos tubulares que formam numerosas câmaras irregulares comunicantes com uma grande cavidade central ocupada, em parte, por secreção homogênea acidófila (Fig.1A).

O epitélio secretor é do tipo pseudoestratificado colunar, com algumas porções formadas por epitélio simples colunar (Fig.2A,B). A lâmina própria é delgada e discreta (evidenciada, em azul, pelo Tricrômico de Masson), que se une aos espessos septos de tecido conjuntivo denso, o que confere ao órgão aparência lobulada. As células colunares são altas, com citoplasma basófilo, núcleo arredondado, com cromatina clara e nucléolo evidente (Fig.2C), e as células basais são esparsas; apresentam citoplasma claro e núcleo pequeno, com intensa basofilia. Observa-se extrusão nuclear em alguns locais.

A túnica muscular é evidente, formada pela camada interna longitudinal delgada e pela camada externa circular espessa, podendo estar mescladas em alguns locais. Aí se observa espessamento da mesma, porém manten- 


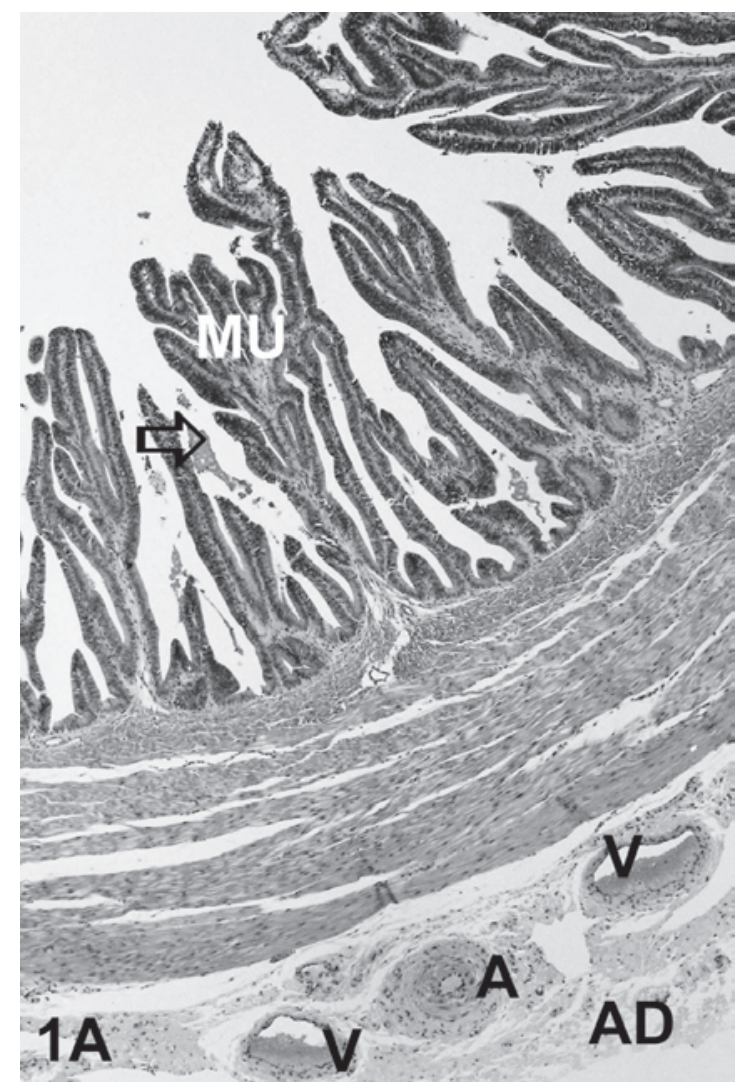

Fig.1A. A estrutura geral da glândula vesicular constituída pelas túnicas mucosa (MU) e adventícia (AD). A túnica mucosa apresenta-se intensamente pregueada delimitando compartimento onde se nota secreção acidófila homogênea (seta). $\mathrm{Na}$ adventícia há pequenos vasos arteriais $(\mathrm{A})$ e venosos (V). HE, 220x. do regularidade na disposição das fibras (evidenciado, em vermelho, pelo Tricrômico de Masson). As células musculares mostram citoplasma acidófilo e núcleo alongado com cromatina granular.

A túnica adventícia é típica (Fig.1A), formada por tecido conjuntivo frouxo, células adiposas, numerosos e pequenos vasos sanguíneos.

Próstata. A parte secretora é tubular e a mucosa apresenta pregas complexas, formando numerosas câmaras irregulares, que se abrem numa grande cavidade central, ocupada, em parte, por secreção homogênea acidófila (Fig.3A,B). O epitélio secretor é do tipo pseudoestratificado colunar, com algumas porções formadas por epitélio colunar simples. As células cilíndricas são altas com citoplasma basófilo, núcleo arredondado com cromatina clara e nucléolo evidente; e as células basais, que são esparsas, apresentam citoplasma claro e núcleo pequeno, com intensa basofilia. Observa-se extrusão nuclear em alguns locais. A lâmina própria é delgada e discreta e está evidenciada em azul, pela coloração de Tricrômico de Masson. Ela une-se aos espessos septos de tecido conjuntivo denso, conferindo ao órgão aparência lobulada (Fig.3A).

A túnica muscular é evidente formada pela camada interna longitudinal delgada e pela camada externa circular espessa, podendo estar mescladas em alguns locais. Aí se observa espessamento da mesma, porém, mantendo regularidade na disposição das fibras (evidenciado em vermelho, pelo Tricrômico de Masson). As células musculares mostram citoplasma acidófilo e núcleo alongado com cromatina granular.

A túnica adventícia é típica, formada por tecido conjuntivo frouxo, células adiposas, numerosos vasos.
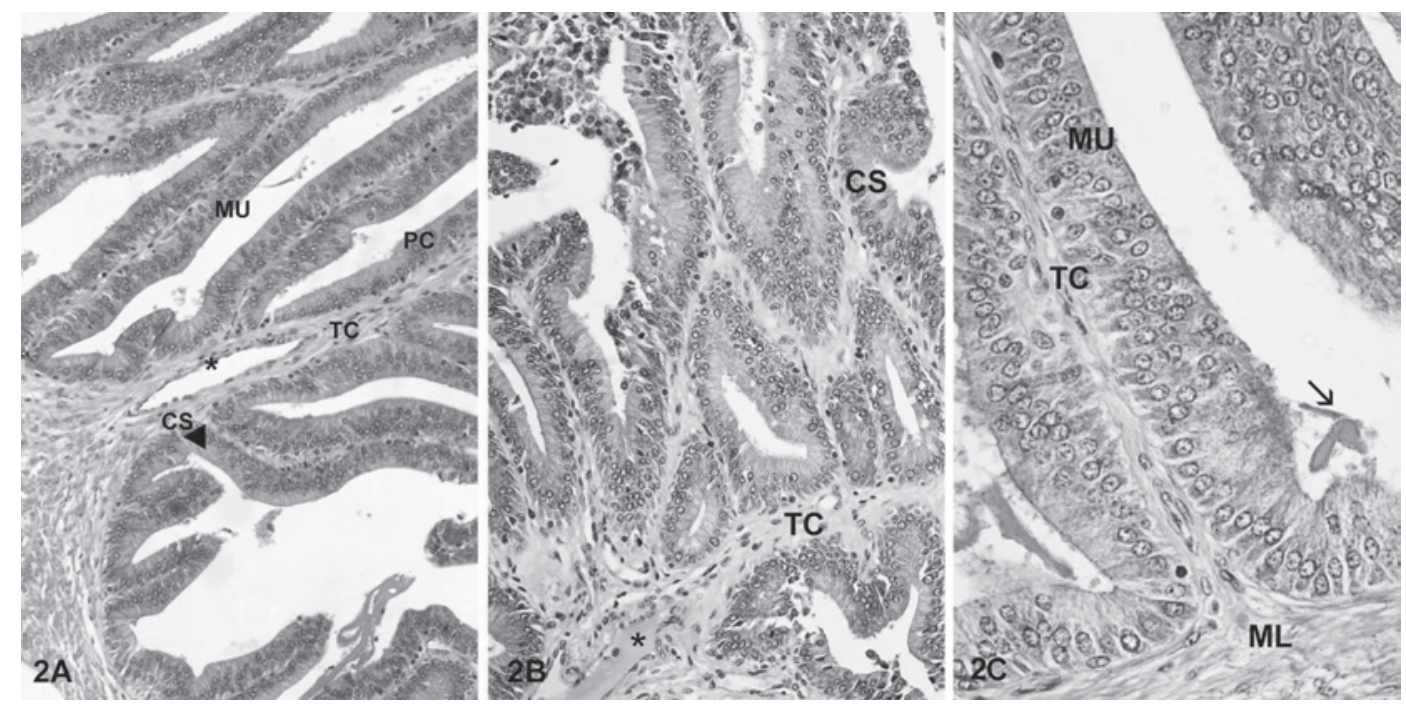

Fig.2A-C. Glândula vesicular. (A,B) Notar o epitélio secretor do tipo pseudoestratificado colunar (PC), embora, em algumas regiões, o mesmo seja do tipo cilíndrico simples (CS seta), apoiado sobre eixo de tecido conjuntivo (TC), contendo vasos $\left({ }^{*}\right) . .(\mathbf{C})$ Em maior aumento, observa-se tanto o núcleo da célula epitelial, arredondado, com cromatina clara e nucléolo evidente quando seu citoplasma basófilo. Nessa mesma figura, nota-se a secreção acidófila na luz do órgão (seta). (MU) mucosa. (A) HE, 220x. (B) HE, 440x. (C) HE, 880x. 


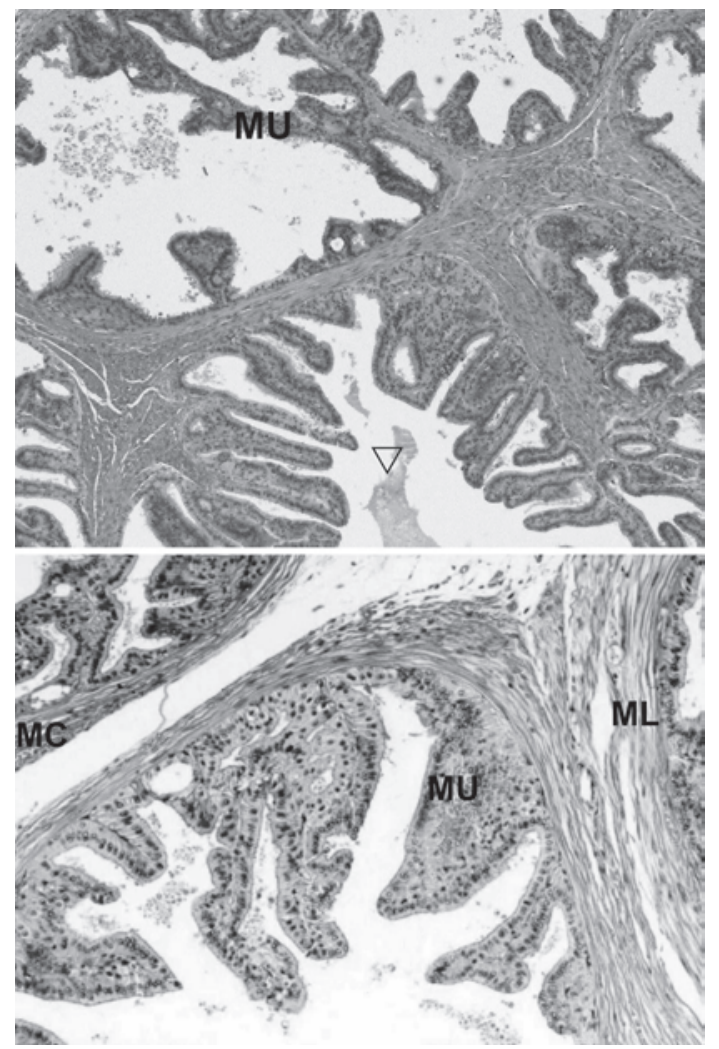

Fig.3A,B. Próstata. (A) A estrutura geral da glândula é constituída pela túnica mucosa (MU) intensamente pregueada, delimitando compartimento onde se nota secreção acidófila homogênea (seta). (B) Pode-se notar a disposição da camada muscular longitudinal (ML) envolvendo os lóbulos da próstata e, externamente a ela, a camada circular (MC). (MU) mucosa. (A) HE, 110x. (B) HE, 220x.

\section{DISCUSSÃO}

As capivaras são animais que mesmo com o avanço dos desmatamentos ainda estão conseguindo se procriar em áreas alagadas que em algumas propriedades rurais são de pouco uso na criação extensiva de alguns animais domésticos e considerando as características biológicas e reprodutivas deste animal, podem ser uma alternativa de criação comercial.

Então, os resultados encontrados no macho da capivara (Hydrochoerus hydrochaeris) sobre as glândulas anexas à uretra masculina são componentes fundamentais ao funcionamento dos órgãos destinados à reprodução animal e preservação das espécies; pois formam o plasma seminal, componente fundamental na preservação e viabilidade do gameta masculino.

A glândula vesicular da capivara (H. hydrochaeris) apresenta-se histologicamente, como peças secretoras tubulares, com mucosa apresentando pregas complexas que formam câmaras irregulares, abrindo-se numa grande cavidade central contendo partes de secreção homogênea acidófila, como descrito por outros autores, como Junqueira \& Martins (1947) e Gude et al. (1982) no rato, e Sprando et al. (1999) no rato de areia (Psammomys obesus).
O epitélio secretor da capivara (H. hydrochaeris) é do tipo pseudoestratificado cilíndrico com algumas porções de epitélio simples cilíndrico. Estas células cilíndricas são altas, também possuem uma lâmina própria delgada e discreta, unida a espessos septos de tecido conjuntivo, a túnica muscular é evidente e a túnica adventícia é formada por tecido conjuntivo frouxo, é semelhante no rato (Junqueira \& Martins 1947, Gude et al. 1982) e na paca (Cuniculus paca) (Matamoros 1981), já segundo outros autores, como Hebel \& Stromberg (1986) no rato, Sprando et al. (1999) no rato de areia (Psammomys obesus) e Menezes et al. (2003), Mollineau et al. (2009) na cutia, o epitélio é simples colunar e a mucosa apresenta uma camada de células colunares altas com grânulos secretórios.

A glândula de coagulação não existe na capivara. No material correspondente este mamífero, de fato não identificamos, histologicamente, qualquer característica que permitisse estabelecer a referida glândula, que provavelmente neste roedor surja como uma expansão da próstata, talvez justificando as alusões de Grassé (1955), que cita apenas a presença das glândulas vesiculares, glândula próstata e glândula de Cowper (glândula bulboeretral) em algumas espécies de roedores e informa que Walker (1910) admite que a coagulação do sêmen é realizada pela ação do líquido das vesículas seminais sobre os lobos anteriores da próstata.

Histologicamente, a próstata da capivara apresentase semelhante às glândulas vesiculares, a não ser em relação à glândula próstata possuir trabéculas de tecido conjuntivo frouxo, que envolve os componente glandulares junto com uma camada de tecido muscular liso, possuindo glândulas de aspecto tubular com luz contendo grânulos acidófilo, mucosa com pregas altas ramificadas, como descrito por Junqueira \& Martins (1947) e Gude et al. (1982) no rato, Matamoros (1981) na paca e Mollineau et al. (2009) na cutia.

Nessa glândula, o epitélio é pseudoestratificado cilíndrico com algumas áreas de epitélio simples cilíndrico, as células são altas e a lâmina própria é bastante delgada, como já citado por estes mesmos pesquisadores. Ao contrário, segundo Hebel \& Stromberg (1986), no rato esta glândula histologicamente não é homogênea, contendo na parte dorsal estreito epitélio colunar pseudoestratificado com ácinos, na periferia epitélio cubóide e dentro das dobras contorcidas e medialmente, amplo epitélio cubóide com ácinos, e de acordo com Soprando et al. (1999), no rato de areia (Psammomys obesus) a glândula próstata ventral contem células simples colunares com prolongamentos e a próstata dorsal contem baixo epitélio colunar, e ainda Menezes et al. (2003), Mollineau et al. (2009) descrevem que o epitélio varia de colunar a pseudoestratificado, com altura do epitélio bastante variável.

De um modo geral, vários artigos destes pesquisadores nos roedores descrevem a presença da glândula bulbouretral na região da base do pênis, como um par de pequenas e globosas glândulas cujos ductos se abrem na superfície dorsal da uretra flexuosa de maneira inver- 
sa. Na capivara como já descreveu Ojasti (1973), as glândulas bulbouretrais (glândulas de Cowper) não são identificadas, porém, se a capivara as possui, seu tamanho deve ser reduzido ou sua inserção é bem oculta pelos músculos da raiz do pênis. Na descrição da localização da glândula bulbouretral de cutia Menezes et al. (2003) e Mollineau et al. (2009) informam que estão dorsolateralmente ao reto, dorsocranialmente aos músculos do esfíncter anal, lateralmente à raiz da cauda, e coberta dorsalmente apenas pela cútis e o tecido subcutâneo, o que as tornam superficiais na região dorsal, na raiz da cauda, fato não descrita na capivara, conforme (Ojasti 1973), cuja informação não se afasta das nossas observações, embora no tratado de Grassé (1955) o autor represente esquematicamente a glândula bulbouretral em algumas espécies de roedores como no rato e no castor canadense.

\section{CONCLUSÕES}

Machos de capivaras (Hydrochoerus hydrochaeris) possuem glândulas vesiculares e próstata como glândulas uretrais. No material examinado não foi identificado epitélio secretor correspondente a glândula bulbouretral. Morfologicamente assemelha-se aos outros histricomorfos.

A capivara apresenta glândulas vesiculares com epitélio secretor do tipo pseudoestratificado colunar, em algumas porções formadas por epitélio simples colunar. A próstata apresenta um epitélio pseudoestratificado colunar e algumas áreas de epitélio simples colunar. Tanto a glândula vesicular quanto a glândula próstata apresenta peças secretoras tubulares, com mucosa pregueada e a luz ampla com conteúdo granular acidófilo.

\section{REFERÊNCIAS}

Alho C.J.R. 1986. Criação e manejo de capivaras em pequenas propriedades rurais. Embrapa-DDT, Brasília. 48p.

Behmer O.A., Tolosa E.M.C. \& Freitas Neto A.G. 1976. Manual de Técnicas para Histologia Normal e Patológica. EdiArt, Editora da USP, São Paulo. 241p.

Borges E.M. 2004. Morfologia dos órgãos genitais masculinos de paca (Agouti paca Linnaeus, 1766). Tese em Anatomia dos Animais Domésticos e Silvestres, Departamento de Cirurgia da Faculdade de Medicina Veterinária e Zootecnia, USP, São Paulo, SP. 165p.

Brasil 2008. Instituto Brasileiro do Meio Ambiente e dos Recursos Naturais Renováveis. Disponível em <http://www.ibama.gov.br/fauna-silvestre/manejo-de-fauna-em-cativeiro> Acesso em 6 out. 2009.
Conceição R.A., Ambrósio C.E., Martins D.S., Carvalho A.F., Franciolli A.L.R., Machado M.R.F., Oliveira M.F. \& Miglino, M.A. 2008. Morphological aspects of yolk sac from rodents of Hystricomorpha subordem: paca (Agouti paca) and agouti (Dasyprocta aguti). Pesq. Vet. Bras. 28:253-259.

Grassé P. 1955. Traité de Zoologie. Anatomie, Systématique, Biologié. Masson et Cie Éditeurs, Paris, p.1323-1525.

Greene E.C. 1955. Anatomy of the Rat. Hafner Publ., New York, p.91, 104.

Gude W.D., Cosgrove G.E. \& Hirsch G.P. 1982. Histological Atlas of the Laboratory Mouse. Plenum Press, New York, p.16-79.

Hebel R. \& Stromberg M.V. 1986. Anatomy and Embriology of the Laboratory Rat. BioMed Verlag, Wörthesee. 270p.

ICVHN 1994. Nomina Histologica, $2^{\text {nd }}$ ed. International Committee on Veterinary Histological Nomenclature, Ithaca, NY, p.21.

Junqueira L.C.U. \& Martins E.O. 1947. Atlas de Anatomia Microscopia do Rato. USP, São Paulo, p.62-73.

Kanashiro C., Santos T.C., Miglino M.A. \& Carter A.M. 2009. Growth and development of the placenta in the capybara (Hydrochoerus hydrochaeris). Reprod. Biol. Endocrinol. 7:57.

Matamoros Y. 1981. Anatomia e histologia del sistema reproductor del tepezcuinte (Cunicullus paca). Revta Biol. Trop., San Jose, 29(1):155164.

Menezes D.J.A., Carvalho M.A.M., Assis-Neto A.C., Oliveira M.F., Farias E.C., Miglino M.A. \& Medeiros J.X. 2003. Morfologia dos órgãos genitais externos do macho de cutia (Dasyprocta aguti Linnaeus, 1766). Braz. J. Vet. Res. Anim. Sci. 40 (Supl.2):148-153.

Miglino M.A., Carter A.M., Ambrósio C.E., Bonatelli M., Oliveira M.F., Ferraz R.H.S., Rodrigues R.F. \& Santos T.C. 2004. Vascular organization of the hystrichomorph placenta: A comparative study in the agouti, capybara, guinea pig, paca and capybara. Placenta 25(5):438-448.

Miglino M.A., Franciolli A.L.R, Oliveira M.F., Ambrósio C.E., Bonatelli M., Machado M.R.F. \& Mess A. 2008. Development of the inverted visceral yolk sac in three species of Caviids (Rodentia, Caviomorpha, Caviidae). Placenta 29:748-752.

Mollineau W.M., Adogwa A.O. \& Garcia G.W. 2009. The Gross and micro anatomy of the accessory sex glands of the male agouti (Dasyprocta leporina). Anat. Histol. Embryol. 38:204-207.

Mollineau W.M., Adogwa A.O., Jasper N., Young K. \& Garcia G.W. 2006. The gross anatomy of the male reproductive system of a neotropical rodent: The agouti (Dasyprocta leporina). Anat. Histol. Embryol., 35:47-52

Ojasti J. 1973. Estudio biológico del chigüira o capibara. Ediciones del Fondo Nacional de Investigaciones Agropecuárias, Caracas. 275p.

Rodrigues R.F., Carter A.M., Ambrósio C.E., Santos T.C. \& Miglino M.A. 2006. The subplacenta of the red-rumped agouti (Dasyprocta leporina L). Reprod. Biol. Endocrinol. 4:31.

Soprando R.L., Collins T.F.X., Black T.N., Olejnik N., Rorie J.L., West L.J., Bowers J.D., Sass N. \& Robl M. 1999. Light microscopic observations on the reproductive tract of the male sand rat, Psammomys obesus. Tissue and Cell 31(1):99-115. 